Research Paper

\title{
HGF/c-Met Signaling Mediated Mesenchymal Stem Cell-induced Liver Recovery in Intestinal Ischemia Reperfusion Model
}

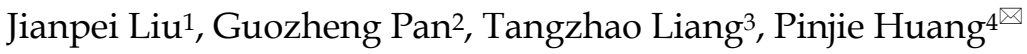 \\ 1. Department of Gastrointestinal Surgery; \\ 2. Liver Transplantation Center; \\ 3. Department of Articular Surgery; \\ 4. Department of Anesthesiology, The Third Affiliated Hospital of Sun Yat-sen University, Guangzhou, China \\ $\square$ Corresponding author: Pinjie Huang, M.D., Department of Anesthesiology, The Third Affiliated Hospital of Sun Yat-sen University, \\ NO.600 TianHe road, Guangzhou 510630, China. E-mail: liujpei2@mail.sysu.edu.cn.
}

(C) Ivyspring International Publisher. This is an open-access article distributed under the terms of the Creative Commons License (http://creativecommons.org/ licenses/by-nc-nd/3.0/). Reproduction is permitted for personal, noncommercial use, provided that the article is in whole, unmodified, and properly cited.

Received: 2013.II.27; Accepted: 2014.03.25; Published: 2014.04.24

\begin{abstract}
Purpose: Liver injury triggered by intestinal ischemia-reperfusion (IIR) usually presage multiorgan dysfunction and death in patients. Recent studies suggest mesenchymal stem cells (MSCs) possess a protective potential against organ damage. Since relative evidence is insufficient and the mechanism is not well understood, we investigated the effect of hepatocyte growth factor c-Met signaling (HGF/c-Met) on recruitment of MSCs and subsequent protection against liver injury triggered by IIR in a rat model.

Methods: IIR models were built as rats were subjected to $75 \mathrm{~min}$ of superior mesenteric artery occlusion and subsequent $4 \mathrm{~h}$ reperfusion. Either of pure MSCs and MSCs pretreated with HGF or SUI I 274 (c-Met inhibitor) were injected into rat models. Biochemical and pathologic alterations of liver in IIR model were measured to evaluate the therapeutic effect of MSCs and drug treatment. Concurrently, the effect of HGF and SUII 274 on c-Met and phosphorylated Met expression in MSCs and MSCs migration were assessed in in vitro experiment.

Results: IIR-induced liver injury was manifested by significant increase in serum ALT, AST and HGF levels as well as pathological change. MSCs with highly c-Met expression ameliorated the increase of serum transaminase levels and hepatic histopathological change, while SUI I 274 weaken these effects. HGF upregulated c-Met and phosphorylated Met expression in MSCs and enhanced its liver protection effect. Transwell assays demonstrated HGF promoted MSCs migration, which was blocked by SUII 274.

Conclusions: HGF/c-Met signaling pathway plays an essential role in the homing of MSCs towards injured liver triggered by intestinal ischemia-reperfusion, and then mediates MSC-induced liver repair.
\end{abstract}

Key words: Mesenchymal stem cell, ischemia reperfusion, intestine, liver injury, hepatocyte growth factor

\section{Introduction}

Intestinal ischemia-reperfusion (IIR) injury is a serious and common clinical event and can occur from different pathophysiologic factors, including superior mesenteric artery (SMA) occlusion, hemorrhagic shock or small bowel transplantation [1]. This condition may lead to severe local and remote tissue injury and subsequent distant organ dysfunction, including the liver $[2,3]$. It is reported that mortality for acute mesenteric ischemia patients is up to $60-80 \%$ [4]. Until now, no therapeutic protocol has proven to 
modify the course of this condition. Understanding and ultimately ameliorating IIR is crucial to improving outcomes after this injury. Liver is likely to bear the brunt of IIR injury since it is supplied by dual blood systems from the bowels $[5,6]$. Several publications have demonstrated that oxidative stress and inflammatory response play a critical role in liver injury triggered by small intestinal ischemia reperfusion $[5,7,8]$. However, the mechanism has yet to be elucidated.

Mesenchymal stem cell (MSC) research has expanded greatly since 1970s, when Friedenstein et al. described an adherent, nonhematopoietic cell type present in the bone marrow (BM) of different species that could form fibroblasts in vitro [9]. MSCs show great promise as a biological therapeutic for a diverse range of unmet medical needs. Many factors contribute to this promise of MSCs, including the easy isolation and expansion of these cells in culture, their multilineage potential, ability to evade the host immune response recognition, paracrine effects, immunomodulatory properties, migratory behavior, and nonethical considerations [10, 11]. Stem cell therapy has become a novel strategy for the treatment of various diseases. So far, several studies involving a variety of animal models have shown beneficial effects of MSC-based therapy on tissue structural repair, including bone, myocardial tissue, skin, kidney and liver [12-16].

Hepatocyte growth factor/ scatter factor c-Met signaling pathway (HGF/ c -Met) supports diverse biological processes including development, proliferation, scattering, and branching morphogenesis [17-19]. Several studies had demonstrated protective effect of HGF on liver damage [20-22].

In the present study, we investigated whether systemic infusion of mesenchymal stem cells led to a hepatoprotective response in liver injury triggered by intestinal ischemia-reperfusion (IIR) in a rat model. Using in vivo and in vitro assays, we demonstrated the effect of HGF and c-Met inhibitor on migration of rat mesenchymal stem cells and its protection against liver injury triggered by IIR.

\section{Materials and Methods}

\section{Experimental model}

This study was approved by the Institutional Animal Care and Use Committee of Sun Yat-Sen University in Guangzhou, China, and followed the national guidelines for the treatment of animals. Fourty healthy male adult Sprague-Dawley rats weighing 180-270 $\mathrm{g}$ were raised by basic diet for a week at stable room temperature $\left(25-27^{\circ} \mathrm{C}\right)$, illuminated from 8:00 am to 8:00 pm. All rats were anesthe- tized with $10 \%$ Choloral hydrate at a dose of 3.5 $\mathrm{ml} / \mathrm{kg}$ intraperitoneal injection after they were fasted for $16 \mathrm{~h}$. In IIR group, the abdomen was opened and superior mesenteric artery (SMA) was identified and clamped for $75 \mathrm{~min}$, then the clamp was released and incision was closed. Reperfusion was initiated by removing the clamp following the ischemia (for various periods of time). In sham-operated group (SHAM group), abdomen was opened and SMA was isolated without clamping.

According to our previous study [23], a total of 3 $\times 10^{6}$ MSCs suspended in $500 \mu \mathrm{L}$ PBS were injected via the tail vein (MSC group) $2 \mathrm{~h}$ before the surgical operation. For control, the same amount of PBS without MSC was infused into SHAM and IIR group by the same route. For MSC+HGF or MSC + SU11274 group, MSCs were incubated with recombinant HGF (25 ng/ml, Peprotech) for $4 \mathrm{~h}$ or SU11274 (2.5 $\mu \mathrm{mol} / \mathrm{l}$, Sigma) for $1 \mathrm{~h}$ respectively, then $3 \times 10^{6}$ MSCs suspended in $500 \mu \mathrm{L}$ PBS were injected via the tail vein 2 $h$ before the surgical operation.

At the end of the specified reperfusion period, eight rats per group were sacrificed at predetermined time points $(6 \mathrm{~h}$ and $72 \mathrm{~h})$ of reperfusion to collect serum and liver samples.

\section{Isolation of rat MSCs}

Bone marrow from femur and tibia cavities of Sprague-Dawley rats was flushed with DMEM (Gibco, Rockville, MD) containing 10\% fetal bovine serum (FBS; Gibco) plus penicillin/streptomycin (100 U/mL $/ 0.1 \mathrm{mg} / \mathrm{mL}$, Gibco), and the cell suspension was centrifuged ( $200 \mathrm{~g}, 5 \mathrm{~min})$. The cells were then plated in flasks $\left(200,000\right.$ cells $\left./ \mathrm{cm}^{2}\right)$. Nonadherent cells were removed after $48 \mathrm{~h}$, and MSC were purified by their capacity to adhere highly to plastic culture flasks.

\section{Characterization of rat MSCs}

The MSC phenotype was confirmed by their typical spindle-shaped appearance and by differentiation into osteocytes and adipocytes with specific differentiation media (protocol described later). For western blot, total cell lysates were prepared by lysing the cells with the buffer (1\% SDS, $10 \mathrm{mM}$ Tris-Cl, $\mathrm{pH}$ $7.6,20 \mathrm{mg} / \mathrm{ml}$ aprotenin, $20 \mathrm{mg} / \mathrm{ml}$ leupeptin and 1 $\mathrm{mM}$ PMSF). The protein concentrations were determined using the Bradford method. About $80 \mu \mathrm{g}$ of protein were separated on 10\% SDS-PAGE gels, and transferred to PVDF membranes. After being blocked with $10 \%$ non-fat milk, the membranes were incubated with anti-c-Met polyclonal antibody (1:200 dilution; Santa Cruz), anti-CD11b polyclonal antibody (1:200 dilution; Santa Cruz), anti-CD34 polyclonal antibody (1:200 dilution; Santa Cruz) and anti-CD45 polyclonal antibody (1:200 dilution; Santa Cruz) at 
$4^{\circ} \mathrm{C}$ overnight. After three 10-min washes, the membranes were incubated with goat anti-rabbit IgG (1:5000 dilution) for $1 \mathrm{~h}$ at room temperature. The signals were developed with the ECL kit (Amersham Pharmacia Biotechnology Inc, Milpitas, CA), using anti- $\beta$ actin antibody (Santa Cruz, CA, USA) as an internal control. Passages 3-5 of MSCs were used for all experiments.

\section{C-Met and pMET detection in MSCs treated with HGF and SU I I 274}

MSCs were cultured in 6-well plates at a density of $1-2 \times 10^{5}$ cells $/ \mathrm{cm}^{2}$ overnight. Then, the cells were treated with recombinant HGF $(25 \mathrm{ng} / \mathrm{ml})$ for $4 \mathrm{~h}$ or SU11274 $(2.5 \mu \mathrm{mol} / 1)$ for $1 \mathrm{~h}$ respectively before being lysed. Another group of MSCs cultured in 6-well plates without drug treatment was set up as control. After that total cell lysates were prepared and western blot were performed according to the same procedure described in the previous paragraph. Anti- phosphorylated Met antibody (Tyr1234/1235) (1:5000 dilution) were from Cell-Signaling Technology (Beverly, MA, USA).

\section{HGF detection in liver tissue}

Liver tissues were made into homogenates with cold normal saline, and then spun at 4000 revolutions/min for 15 minutes. Supernatants were transferred into fresh tubes for detection. Liver total protein was measured by BCA Protein Assay Kit provided by KenGen Biotech Company, Nanjing, China. The concentration of protein in the liver was expressed as $\mu \mathrm{g} / \mathrm{ml}$. The content of HGF was measured by ELISA kits (R\&D systems Inc, USA). The absorbance was read at $450 \mathrm{~nm}$ by a Biokinetics microplate reader Model EL340 (Biotek Instruments, USA). The liver tissue level of HGF was expressed as ng/g protein.

\section{Measuring serum liver enzymes levels}

Two ml blood was obtained from the inferior vena cava, frozen at $-20{ }^{\circ} \mathrm{C}$ for 5 minutes and centrifuged for 15 minutes at 4,000 revolutions/min. Supernatants were transferred into fresh tubes for evaluation. The activities of alanine aminotransferase (ALT, a specific marker for hepatic parenchymal injury), and aspartate Aminotransferase (AST, a nonspecific marker for hepatic injury) in serum were determined in units per liter using automatic biochemistry analyzer (Abbott Laboratories, Abbott Park, IL, USA).

\section{Histopathological evaluation}

Paraffin-embedded samples were sectioned at 4 $\mu \mathrm{m}$ thick slices and stained with hematoxylin and eosin for light microscopic examination. The hepatic histophathological changes were assessed under light microscopy by two pathologists who were blinded to the experiment. Five randomly areas were selected to evaluate the damages of liver induced by IIR through the following standard12: Grade 0: Normal structure of hepatic lobule, hepatocyte, hepatic cords, central vein and hepatic sinus. Grade 1: Some degeneration of liver cells and some inflammatory cells infiltrate in the portal area. Grade 2: Blood stasis in central vein and hepatic sinus, scattered degeneration or necrosis of liver cells, and more inflammatory cells infiltrate in the liver tissues, and the hepatic lobule is integrity. Grade 3: Blood stasis in central vein and hepatic sinus, extensive degeneration or necrosis of liver cells, and a large number of inflammatory cells infiltrate in the liver tissues, and parts of the hepatic lobule are broken.

\section{Transwell migration assay}

Transwell migration assays were performed in transwell inserts with $8 \mu \mathrm{m}$ pore uncoated membrane filters (Corning Incorporated, Corning, NY, USA). MSC were trypsinized, resuspended in serum-free DMEM, and transferred to the upper chamber $\left(5 \times 10^{4}\right.$ cells resuspended in $1.0 \mathrm{~mL}$ DMEM) (control group). For SU11274 group, $5 \times 10^{4}$ cells resuspended in $1.0 \mathrm{~mL}$ DMEM containing $2.5 \mu \mathrm{mol} / 1$ SU11274 were added to the upper chamber. An equal volume maintenance medium supplemented with $5,25,50 \mathrm{ng} / \mathrm{ml}$ of HGF was added to the lower chamber. The cells were allowed to migrate for $24 \mathrm{~h}$ in a humidified $\mathrm{CO}_{2}$ incubator at $37^{\circ} \mathrm{C}$. Following incubation, the media were aspirated, and the cells remaining on the upper surface of the filter were removed with a cotton swab; the cells that had migrated to the lower surface were stained with crystal violet for $30 \mathrm{~min}$. The average numbers of migrated cells were determined by counting the cells in 6 random high-power fields $(\times 200)$. The transwell assays for each condition were performed in triplicate and representative results are shown.

\section{Statistical analysis}

Data analysis was performed with a personal computer with SAS 8.1 software. The data were all analyzed by normality test and homogeneity test of variances. Measurement data of normal distribution were expressed as mean $\pm \mathrm{SD}$. One way analysis of variance (one-way ANOVA) was used to compare values among multiple groups and the Student-Newman-Keuls (SNK) test was used for pairwise comparison. A value of $\mathrm{P}<0.05$ was considered statistically significant. 


\section{Results}

\section{Characterization of rat MSCs}

Rat MSCs were identified by western blot analysis and the mesenchymal lineage differentiation. Rat MSCs expressed CD54 and CD90 and did not express CD34. Rat MSCs also could be differentiated into osteoblasts and adipocytes. (Figure 1)
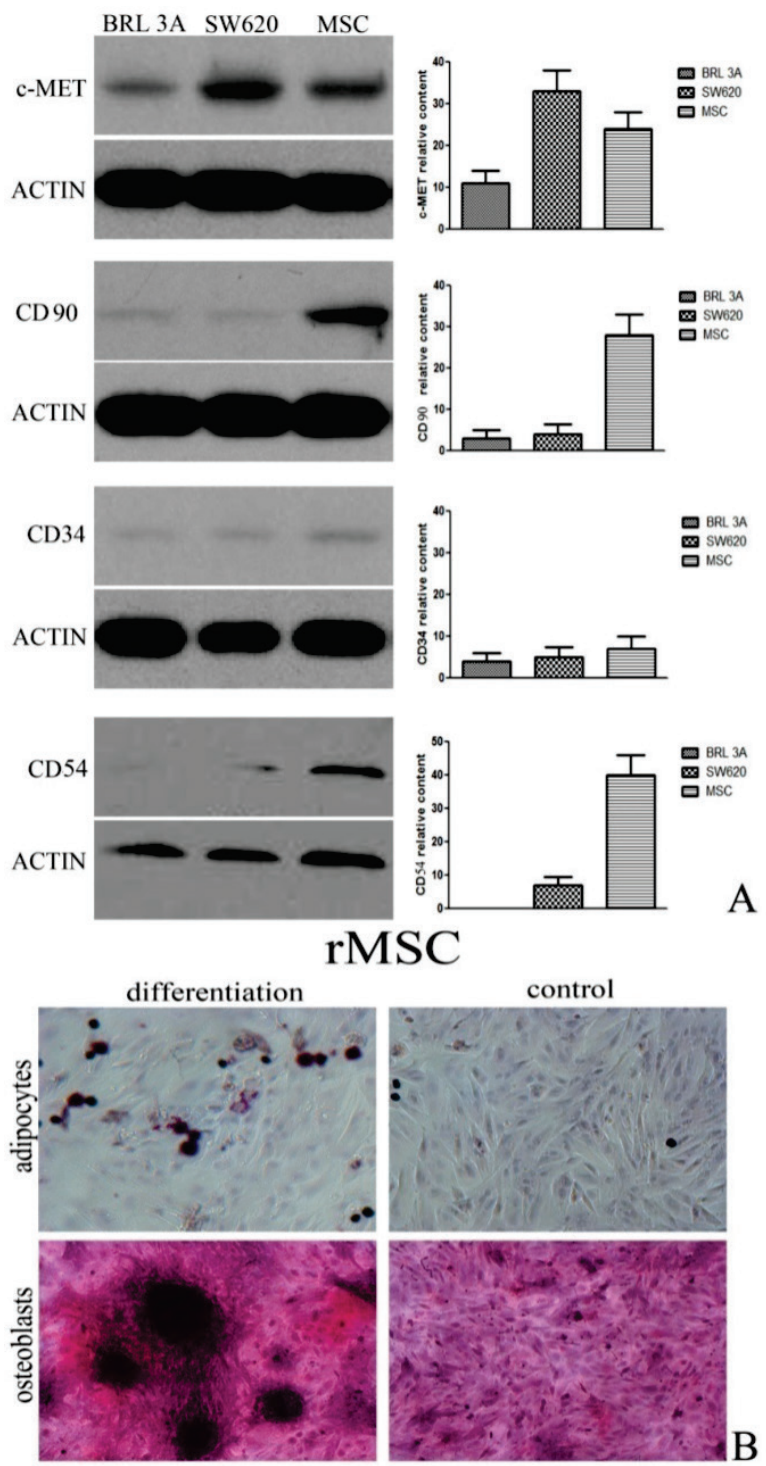

Figure I Characterization of rat MSCs. (A) Immunophenotype of rat MSCs, SW620 cells and BRL 3A cells. Cells were labeled with the antibodies specific for the indicated rat surface antigens or negative controls, and analyzed by western blot. $\beta$-actin was used as an internal control. (B) Rat MSCs were induced to differentiate into osteoblasts stain positive for calcium with alizarin red solution. Under adipogenic conditions, rMSCs differentiate into adipocytes, which are positively stained by oil red staining. Original magnification, $\times 400$. The results shown are representative of three experiments that had similar results.

\section{Rat MSCs reduced the release of serum enzymes in rats with IIR}

The release of ALT, AST enzymes, markers for liver injury, was measured by a clinical biochemistry analyzer. At $6 \mathrm{~h}$ after the operation, the serum AST, ALT levels in the rats of IIR group were significantly higher than those of the rats in SHAM group (Figure 2). In contrast, the serum AST, ALT levels induced by IIR were greatly decreased in the MSC group and MSC+HGF group at $6 \mathrm{~h}$ after the operation. The serum AST, ALT levels in MSC+HGF group were significantly lower than those in MSC group. For MSC + SU11274 group, the serum AST, ALT levels were just between those of IIR group and MSC group. At $72 \mathrm{~h}$ after the operation, the increased serum AST and ALT levels in the five groups gradually recovered, but the trend was similar to that at $6 \mathrm{~h}$, except for the difference between MSC group and MSC+HGF group was no more statistically significant.

\section{Rat MSCs improved the histopathologic changes in the liver of rats with IIR}

Histopathologic analysis showed no pathologic findings in the sham group. The histologic changes induced by IIR were examined, including necrosis of liver cells, inflammatory cells infiltration and integrity of hepatic lobule. After $6 \mathrm{~h}$ of reperfusion, the rats in the IIR group showed higher hepatocellular necrosis, while the rats in the MSC group and MSC+HGF group still had large areas of normal liver architecture, like the rats in the SHAM group. Although the rats in the MSC+SU11274 group have minor liver histopathologic changes than IIR group, more necrosis of liver cells and more inflammatory cells infiltrate in the liver tissues were discovered comparing with the rats in MSC group. After $72 \mathrm{~h}$ of reperfusion, liver histopathologic scores were decreased in all groups, yet differences of histopathologic scores between the SHAM group, IIR group and MSC group were still obvious. (Figure 2 and Table 1 )

Table I Mesenchymal stem cells improved the histopathologic scoring in the liver of rats with intestinal ischemia-reperfusion.

\begin{tabular}{|c|c|c|}
\hline & $\begin{array}{l}\text { Liver histopathologic } \\
\text { score at } 6 \mathrm{~h} \text { after reperfu- } \\
\text { sion }\end{array}$ & $\begin{array}{l}\text { Liver histopathologic } \\
\text { score at } 72 \mathrm{~h} \text { after reper- } \\
\text { fusion }\end{array}$ \\
\hline SHAM group & $0.5 \pm 0.20$ & $0.0 \pm 0.0$ \\
\hline IIR group & $3.8 \pm 0.5$ & $1.1 \pm 0.3$ \\
\hline MSC group & $1.5 \pm 0.3$ & $0.4 \pm 0.12$ \\
\hline MSC+HGF group & $1.0 \pm 0.25$ & $0.4 \pm 0.2$ \\
\hline MSC+SU11274 group & $2.9 \pm 0.35$ & $0.6 \pm 0.14$ \\
\hline $\mathrm{P}^{*}$ & $<0.01$ & $<0.01$ \\
\hline$P^{* *}$ & $<0.01$ & $<0.01$ \\
\hline $\mathrm{P}^{* * *}$ & $<0.01$ & $>0.05$ \\
\hline $\mathrm{P}^{* * * *}$ & $<0.01$ & $>0.05$ \\
\hline \multicolumn{3}{|c|}{$\begin{array}{l}\text { * indicates comparison of SHAM group versus IIR group, }{ }^{* *} \text { indicates comparison } \\
\text { of IIR group versus MSC group, }{ }^{* * *} \text { indicates comparison of MSC group versus } \\
\text { MSC+HGF group, }{ }^{* * * *} \text { indicates comparison of MSC group versus MSC+SU11274 } \\
\text { group. }\end{array}$} \\
\hline
\end{tabular}



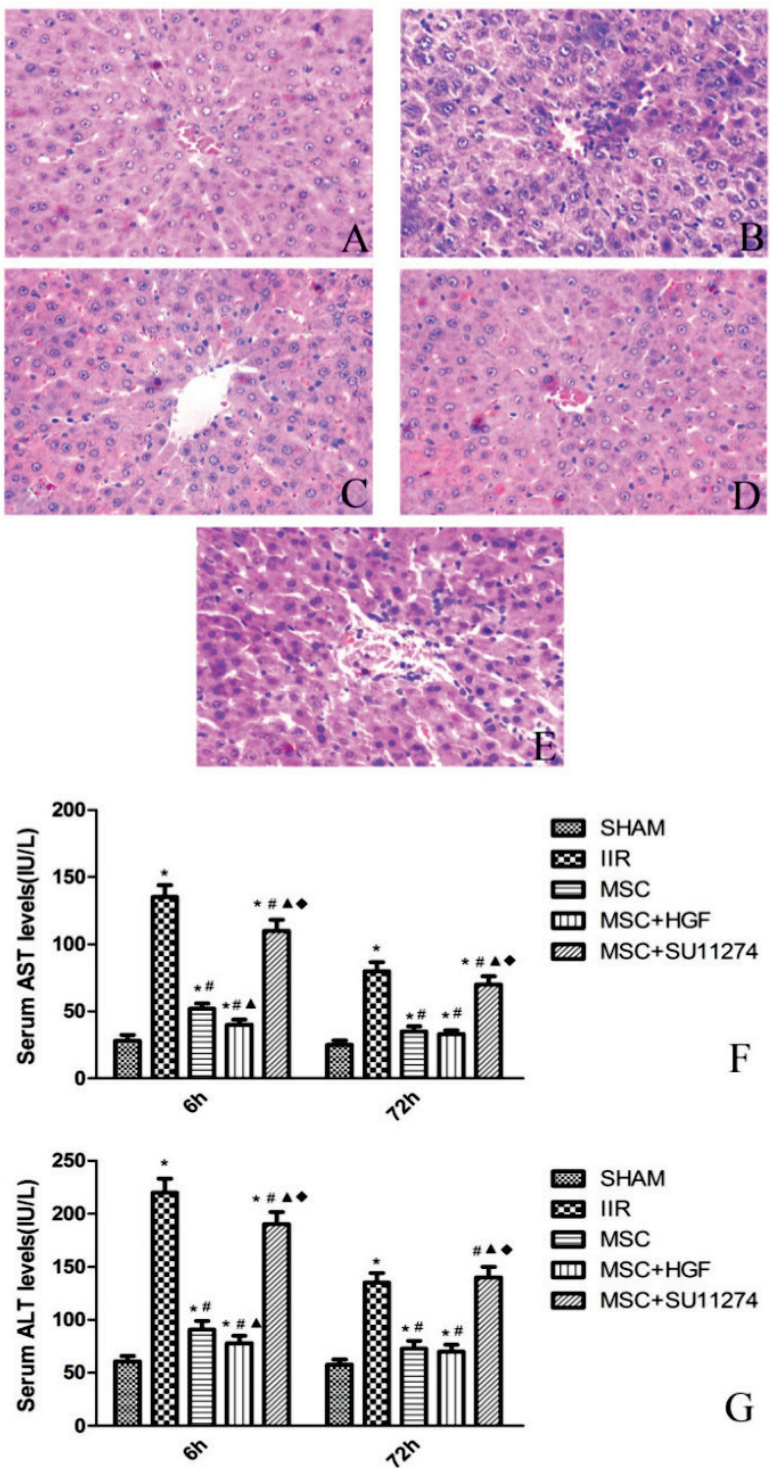

Figure 2 Rat MSC improved the histopathologic changes of the liver and reduced the release of serum enzymes in rats with IIR. Representative histologic appearances of the liver from the SHAM group (A), IIR group (B), MSC group (C), MSC+HGF group (D) and MSC + SUII 274 group (E) at $6 \mathrm{~h}$ after reperfusion following $75 \mathrm{~min}$ of intestinal ischemia (HE staining) (magnification $\times 400$ ). Normal hepatic architecture was observed in rats in the SHAM group. After $6 \mathrm{~h}$ of reperfusion, IIR group and MSC + SUII 274 group rats had higher hepatocellular necrosis and more hepatocellular vacuolation and bleb formation with mild neutrophil accumulation, while the MSC group, MSC+HGF group rats still had large areas of normal liver architecture, like the SHAM group rats. As markers for hepatic, serum AST and ALT levels were determined at 6 and $72 \mathrm{~h}$ after reperfusion ( $F$ and $G$ ). The data are represented by mean \pm standard deviation. $n=8$ independent experiments. $p$ values of less than 0.05 were considered to be statistically significant. * indicates $p<0.05$ when compared with SHAM group, \# indicates $p<0.05$ when compared with IIR group, $\boldsymbol{\Delta}$ indicates $p<0.05$ when compared with MSC group, $\diamond$ indicates $p<0.05$ when compared with MSC + HGF group.

\section{HGF upregulated c-Met and phosphorylated Met expression in MSCs}

Western blot results showed that MSCs expressed higher level of c-Met and phosphorylated Met after $4 \mathrm{~h}$ treatment of HGF compared with control group. SU11274 treatment had no effect on c-Met expression in MSCs. (Figure 3)

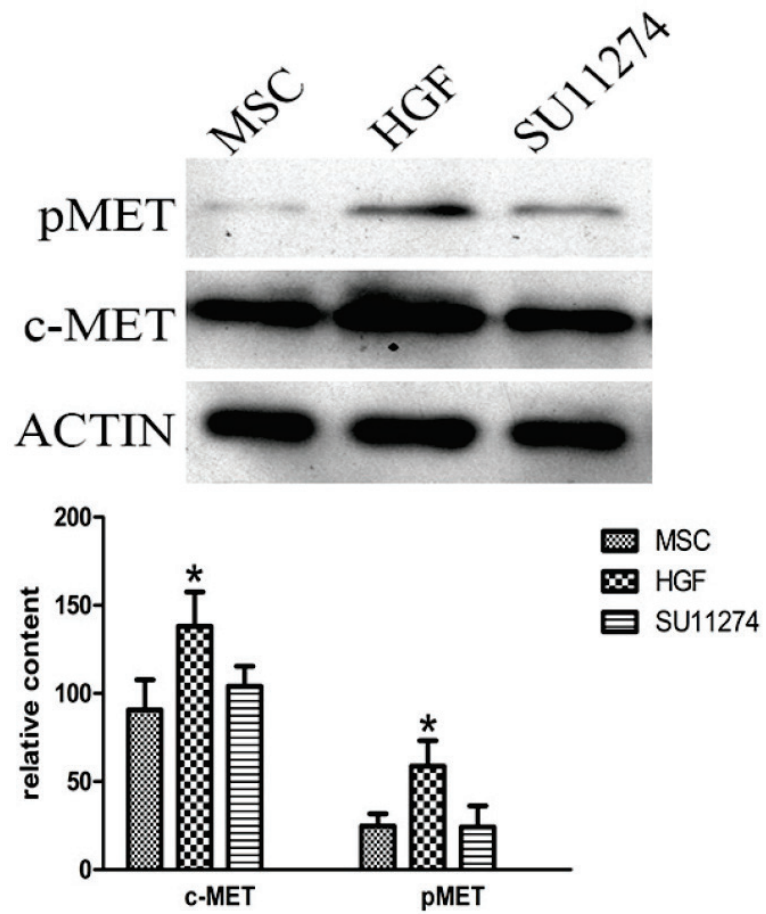

Figure 3 Western blot analysis of c-Met and pMet (Tyr/234//235) in MSCs treated with HGF and SUI I 274. MSCs were cultured in 6-well plates incubated with recombinant HGF $(25 \mathrm{ng} / \mathrm{ml})$ for $4 \mathrm{~h}$ or SUII $274(2.5 \mu \mathrm{mol} / \mathrm{l})$ for $\mathrm{Ih}$ respectively before being lysed. Another group of MSCs cultured in 6-well plates without drug treatment was set up as control. Each column represents the mean \pm standard deviation of at least three determinations. All values are shown as mean \pm standard deviation. * indicates $p<0.05$ when compared with control group.

\section{HGF level was elevated in the liver of rats with IIR}

At $6 \mathrm{~h}$ and $72 \mathrm{~h}$ after reperfusion, hepatic HGF level in the rats of the IIR group increased gradually, while hepatic HGF level in the rats of the SHAM group showed no significantly changed. At $6 \mathrm{~h}$ and 72 $\mathrm{h}$ after reperfusion, the rats in the IIR group all showed markedly higher hepatic HGF level compared with those in the SHAM group. (Figure 4)

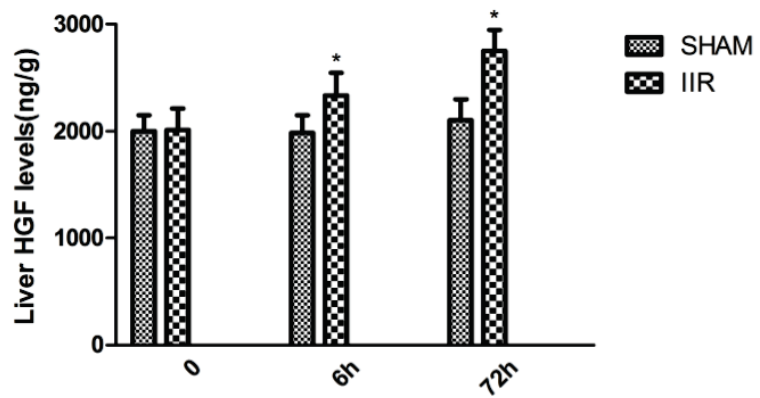

Figure $4 \mathrm{HGF}$ level was elevated in the liver of rats with IIR. At $6 \mathrm{~h}$ and $72 \mathrm{~h}$ after reperfusion, hepatic HGF level in the rats of the IIR group and SHAM operation group were detected by ELISA kits. Each bar represents the mean \pm standard deviation of five determinations. * indicates $p<0.05$ when compared with SHAM group. 


\section{Effect of HGF and c-Met inhibitor on migration of MSCs}

As the concentration of HGF increased, MSC migration increased consequently. The maximum of cells migration was recorded when the concentration of HGF reached $50 \mathrm{ng} / \mathrm{ml}$. As shown in Figure 4, the presence of SU11274 decreased MSC migration. The average migrated cell number of MSC decreased nearly 50\% compared with the controls. (Figure 5)

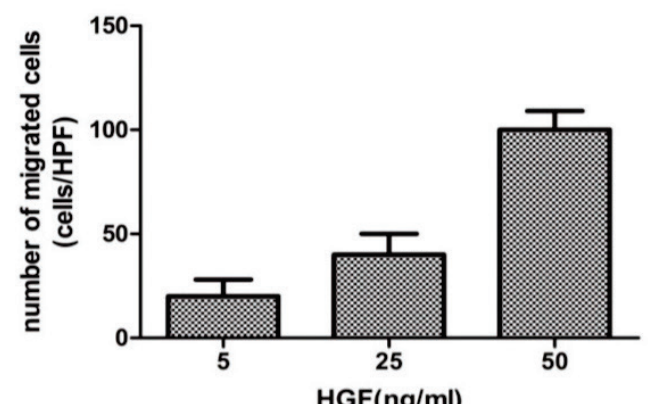

A
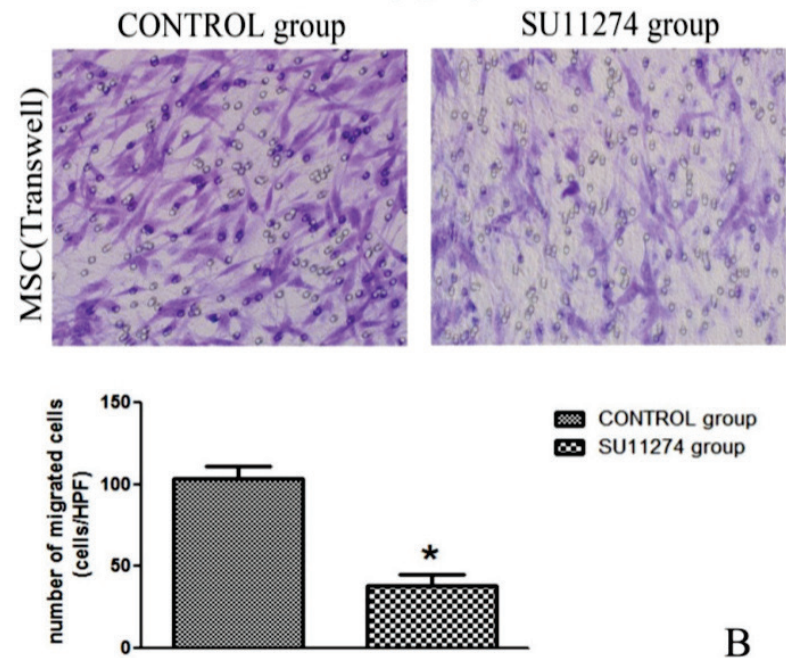

Figure 5 HGF and c-Met inhibitor influenced migration of rMSC. (A)During transwell migration assay, MSCs were exposed to $5,25,50 \mathrm{ng} / \mathrm{ml}$ of HGF (lower chamber) to identify potential chemoattractants. (B)MSCs treated with (SUII 274 group) or without (CONTROL group) $2.5 \mu \mathrm{mol} / \mathrm{I} \mathrm{SUII} 274$ were exposed to $50 \mathrm{ng} / \mathrm{ml}$ of HGF (lower chamber) to identify difference of cell migration. Average numbers of migrated cells were determined by counting the cells in 6 random high-power fields (crystal violet staining, $\times 200$ ). Each bar represents the mean \pm standard deviation of at least three determinations. * indicates $p<0.05$ when compared with CONTROL group.

\section{Discussion}

Intestinal ischemia-reperfusion injury has been demonstrated as a main mechanism in the etiopathogenesis of multiple organ dysfunction syndromes (MODS) as an initiator of remote organ injury [3]. The liver is usually the first injured remote organ affected by IIR because its vasculature is coupled in series with the intestinal circulation [24]. In the present study, IIR-induced liver injury was manifested by significant increase in serum ALT and AST levels as well as pathological liver injury. Hepatic dysfunction often predicts death in patients with IIR and multiple organ dysfunction syndromes. Several lines of evidence had shown that IIR-induced release of toxic substances contribute to post-ischemic liver injury through portal circulation, oxidative stress and inflammatory response were involved as well [25-27]. A number of studies had tried to modify this course, but still no significant progress had been made.

Stem cell therapy has become a novel and potential treatment for various diseases. Previous researches had reported the capacity of MSCs to differentiate into hepatocytes and express surface antigen of hepatocytes [28]. In addition, administration of MSCs could improve liver function after injury [23, 29]. However, few studies have examined the influence of bone marrow MSCs on liver injury induced by intestinal ischemia reperfusion. To the best of our knowledge, this is the first report to show that MSCs may accelerate the structural and functional recovery from liver injury triggered by IIR. In the present study, MSC treatment ameliorated the increase in serum transaminase levels, which serves as the most sensitive marker for clinical and experimental hepatic injury evaluation.

Nowadays, bone marrow still is the richest and most reliable reservoir for MSCs. Multilineage potential, immunomodulatory properties and migratory behavior of bone marrow MSCs have made them attractive for treating organ inflammatory diseases. However, the precise mechanism of MSCs on ischemia/reperfusion-injured tissues remains largely unknown. Previous researches had suggested that engrafted MSCs at injury sites were able to differentiate into multipotential cells and organ-specific cells, then directly contributed to wound healing [14, 30-33]. However, a previous report showed that engrafted MSCs scattered mostly in the hepatic tissue and survived in the liver 4 weeks after transplantation, but did not differentiate into hepatocytes expressing albumin or alpha-fetoprotein [34]. This report suggested that a variety of bioactive cytokines secreted by the transplanted MSCs might be involved in restoring liver function and promoting regeneration. In addition, another report had shown that MSC-conditioned medium (MSC-CM) had the potential to reduce cell death [35]. Moreover, a research concerning ischemia reperfusion induced acute renal failure of rats discovered that the effect of MSCs on renal protection was present at only $72 \mathrm{~h}$ after administration, which was insufficient for MSC differentiation. Furthermore, in a study of MSC differentiation into hepatocyte-like cells in vitro and in vivo, 14 - 21 days were usually required for MSCs to perform hepatocyte differentiation under the conditions used [36]. These findings indi- 
cated that MSCs were viable to function shortly after transplantation. There was limited time for MSCs to trans-differentiate into hepatocytes or hepatocyte-like cells during the acute phase. Therefore, it is unlikely that trans-differentiation is involved in tissue protection and repair at early stage.

Recently the paracrine effects of MSCs, instead of its differentiation effects, have attracted a great deal of attention as the prime mechanism of the beneficial effects [37]. A broad range of growth factors secreted by MSCs, such as HGF, epidermal growth factor (EGF), vascular endothelial growth factor (VEGF), basic fibroblast growth factor (bFGF), and transforming growth factor beta (TGF-b), composes the biologically role of these cells under injury conditions [12, 38-40]. These studies implied that MSCs possess the capacity to secrete soluble factors to alter the tissue microenvironment and may play prominent role in tissue repair. This paracrine hypothesis of MSC is supported by the observation due to these effects occur at a very early stage. Similarly, in our current study, MSCs treatment significantly protected rats from liver injury, even after $6 \mathrm{~h}$ and $72 \mathrm{~h}$ of intestinal reperfusion. Therefore, the application of MSCs seems to be a promising strategy to alleviate acute liver injury triggered by IIR, maybe in part because of their paracrine production of growth factors.

To interpret the involvement of MSCs in tissue regeneration, a hypothesis had been brought up recently that tissue injury may result in the release of various cytokines, which can promote the migration of MSCs into the peripheral blood and then to sites of injury. MSCs which are attracted by chemokines could follow a signal of increasing chemokine concentration towards the source. In this study, c-Met was found to be highly expressed in bone marrow MSCs, while the related ligand, HGF was up-regulated under the IIR-induced liver injury condition in current study. Ligand and receptor interactions may play an important role on the recruitment of MSCs. Furthermore, pretreating MSCs with HGF in this study enhanced MSCs-induced liver protection, while pretreating MSCs with c-Met inhibitor showed an opposite effect. C-Met expression and phosphorylated Met were upregulated by HGF indicated that c-Met may be the reason why HGF enhanced MSCs-induced liver protection. Finally, the present study confirmed that the migration of MSCs in vitro increased as HGF concentration increased, and cellular migration was notably inhibited by blockage of c-Met. All above results support the hypothesis that HGF and c-Met interaction may therefore contribute to the recruitment of bone marrow MSCs to injured liver. HGF would serve as one of the important chemotactic factors for the migration of bone marrow MSCs.

Researchers have reported beneficial effects of MSC-based therapy on liver structural and functional repair [15, 41, 42]. However, the percentage of hepatocytes that trans-differentiated from donor-derived MSCs is actually very low [43]. Our result implied that transplanted MSCs at wound sites may not only able to trans-differentiate into multiple component cell types but also secrete cytokines to stimulate the recovery of the hepatic cells at early stage, so as to contribute to liver regeneration and wound healing. Strategies to mobilize an internalized receptor such as c-Met and increase its functional expression may be useful for improving homing of MSCs to injured tissues. Moreover, discover of HGF/c-Met interaction makes it possible to attract endogenous and engrafted MSCs to a specific site for wound healing and tissue regeneration, which would be an easier, safer and more efficient therapy than traditional cell therapy.

In summary, the present study indicated that MSCs represented a potential therapeutic strategy to alleviate liver injury induced by IIR. HGF/c-Met interaction may contribute to the recruitment of MSCs to injured liver and the following liver protective effects. Our results provide new insights into liver repair based on MSCs treatment, and add new information of developing therapeutic protocols in combating IIR mediated liver injury.

\section{Acknowledgments}

This study was supported by Guangdong Natural Science Foundation Grant (S2012040006569, S2013040016160) and Specialized Research Fund for the Doctoral Program of Higher Education of China (20130171120101).

\section{Competing Interests}

The authors have declared that no competing interest exists.

\section{References}

1. Haglund U, Bergqvist D. Intestinal ischemia -- the basics. Langenbecks Arch Surg. 1999; 384: 233-38.

2. Mallick IH, Yang W, Winslet MC, et al. Ischemia-reperfusion injury of the intestine and protective strategies against injury. Dig Dis Sci. 2004; 49: 1359-77.

3. Harward TR, Brooks DL, Flynn TC, et al. Multiple organ dysfunction after mesenteric artery revascularization. J Vasc Surg. 1993; 18: 459-67, 467-69.

4. Oldenburg WA, Lau LL, Rodenberg TJ, et al. Acute mesenteric ischemia: a clinical review. Arch Intern Med. 2004; 164: 1054-62.

5. Turnage RH, Bagnasco J, Berger J, et al. Hepatocellular oxidant stress following intestinal ischemia-reperfusion injury. J Surg Res. 1991; 51: 467-71.

6. Yao JH, Li YH, Wang ZZ, et al. Proteasome inhibitor lactacystin ablates liver injury induced by intestinal ischaemia-reperfusion. Clin Exp Pharmacol Physiol. 2007; 34: 1102-08.

7. Tomita M, Kishimoto H, Takizawa $\mathrm{Y}$, et al. Effects of intestinal ische$\mathrm{mia} /$ reperfusion on P-glycoprotein mediated biliary and renal excretion of rhodamine123 in rat. Drug Metab Pharmacokinet. 2009; 24: 428-37. 
8. Naito $\mathrm{Y}$, Takagi T, Ichikawa $\mathrm{H}$, et al. A novel potent inhibitor of inducible nitric oxide inhibitor, ONO-1714, reduces intestinal ischemia-reperfusion injury in rats. Nitric Oxide. 2004; 10: 170-77.

9. Friedenstein AJ, Chailakhyan RK, Latsinik NV, et al. Stromal cells responsible for transferring the microenvironment of the hemopoietic tissues. Cloning in vitro and retransplantation in vivo. Transplantation. 1974; 17: 331-40.

10. Brooke G, Cook M, Blair C, et al. Therapeutic applications of mesenchymal stromal cells. Semin Cell Dev Biol. 2007; 18: 846-58.

11. Mias C, Trouche E, Seguelas MH, et al. Ex vivo pretreatment with melatonin improves survival, proangiogenic/mitogenic activity, and efficiency of mesenchymal stem cells injected into ischemic kidney. Stem Cells. 2008; 26: 1749-57.

12. Togel F, Weiss K, Yang $\mathrm{Y}$, et al. Vasculotropic, paracrine actions of infused mesenchymal stem cells are important to the recovery from acute kidney injury. Am J Physiol Renal Physiol. 2007; 292: F1626-35.

13. Cheng $\mathrm{Z}, \mathrm{Ou} \mathrm{L}, \mathrm{Zhou} X$, et al. Targeted migration of mesenchymal stem cells modified with CXCR4 gene to infarcted myocardium improves cardiac performance. Mol Ther. 2008; 16: 571-79.

14. Sasaki M, Abe R, Fujita Y, et al. Mesenchymal stem cells are recruited into wounded skin and contribute to wound repair by transdifferentiation into multiple skin cell type. J Immunol. 2008; 180: 2581-87.

15. Oyagi S, Hirose M, Kojima M, et al. Therapeutic effect of transplanting HGF-treated bone marrow mesenchymal cells into CCl4-injured rats. J Hepatol. 2006; 44: 742-48.

16. Zhao J, Zhang N, Prestwich GD, et al. Recruitment of endogenous stem cells for tissue repair. Macromol Biosci. 2008; 8: 836-42.

17. Michalopoulos GK, DeFrances MC. Liver regeneration. Science. 1997; 276: 60-66.

18. Zhang YW, Vande WG. HGF/SF-met signaling in the control of branching morphogenesis and invasion. J Cell Biochem. 2003; 88: 408-17.

19. Birchmeier C, Gherardi E. Developmental roles of HGF/SF and its receptor, the c-Met tyrosine kinase. Trends Cell Biol. 1998; 8: 404-10.

20. Huh CG, Factor VM, Sanchez A, et al. Hepatocyte growth factor/c-met signaling pathway is required for efficient liver regeneration and repair. Proc Natl Acad Sci U S A. 2004; 101: 4477-82.

21. Valdes-Arzate A, Luna A, Bucio L, et al. Hepatocyte growth factor protects hepatocytes against oxidative injury induced by ethanol metabolism. Free Radic Biol Med. 2009; 47: 424-30.

22. Phaneuf D, Chen SJ, Wilson JM. Intravenous injection of an adenovirus encoding hepatocyte growth factor results in liver growth and has a protective effect against apoptosis. Mol Med. 2000; 6: 96-103.

23. Pan GZ, Yang Y, Zhang J, et al. Bone marrow mesenchymal stem cells ameliorate hepatic ischemia/reperfusion injuries via inactivation of the MEK/ERK signaling pathway in rats. J Surg Res. 2012; 178: 935-48.

24. Pierro A, Eaton S. Intestinal ischemia reperfusion injury and multisystem organ failure. Semin Pediatr Surg. 2004; 13: 11-17.

25. Sheng ZY, Dong YL, Wang $\mathrm{XH}$. Bacterial translocation and multiple system organ failure in bowel ischemia and reperfusion. Chin Med J (Engl). 1991; 104: 897-903.

26. Olanders K, Sun Z, Borjesson A, et al. The effect of intestinal ischemia and reperfusion injury on ICAM-1 expression, endothelial barrier function, neutrophil tissue influx, and protease inhibitor levels in rats. Shock. 2002; 18: 86-92

27. Yao JH, Zhang XS, Zheng SS, et al. Prophylaxis with carnosol attenuates liver injury induced by intestinal ischemia/reperfusion. World J Gastroenterol. 2009; 15: 3240-45.

28. Jung YJ, Ryu KH, Cho KA, et al. In vitro hepatic differentiation of human umbilical cord blood and bone marrow cells. Pediatr Hematol Oncol. 2008; 25: 481-91.

29. Cho KA, Woo SY, Seoh JY, et al. Mesenchymal stem cells restore CCl4-induced liver injury by an antioxidative process. Cell Biol Int. 2012; 36: 1267-74.

30. Chen Y, Shao JZ, Xiang LX, et al. Mesenchymal stem cells: a promising candidate in regenerative medicine. Int J Biochem Cell Biol. 2008; 40: 815-20.

31. Sackstein R, Merzaban JS, Cain DW, et al. Ex vivo glycan engineering of CD44 programs human multipotent mesenchymal stromal cell trafficking to bone. Nat Med. 2008; 14: 181-87.

32. Wojakowski W, Kucia M, Kazmierski M, et al. Circulating progenitor cells in stable coronary heart disease and acute coronary syndromes: relevant reparatory mechanism? Heart. 2008; 94: 27-33.

33. Swenson ES, Guest I, Ilic Z, et al. Hepatocyte nuclear factor-1 as marker of epithelial phenotype reveals marrow-derived hepatocytes, but not duct cells, after liver injury in mice. Stem Cells. 2008; 26: 1768-77.

34. Tsai PC, Fu TW, Chen YM, et al. The therapeutic potential of human umbilical mesenchymal stem cells from Wharton's jelly in the treatment of rat liver fibrosis. Liver Transpl. 2009; 15: 484-95.

35. van Poll D, Parekkadan $\mathrm{B}, \mathrm{Cho} \mathrm{CH}$, et al. Mesenchymal stem cell-derived molecules directly modulate hepatocellular death and regeneration in vitro and in vivo. Hepatology. 2008; 47: 1634-43.

36. Sgodda M, Aurich H, Kleist S, et al. Hepatocyte differentiation of mesenchymal stem cells from rat peritoneal adipose tissue in vitro and in vivo. Exp Cell Res. 2007; 313: 2875-86

37. Togel $\mathrm{F}, \mathrm{Hu} \mathrm{Z}$, Weiss $\mathrm{K}$, et al. Administered mesenchymal stem cells protect against ischemic acute renal failure through differentiation-independent mechanisms. Am J Physiol Renal Physiol. 2005; 289: F31-42.
38. Markel TA, Wang $\mathrm{Y}$, Herrmann JL, et al. VEGF is critical for stem cell-mediated cardioprotection and a crucial paracrine factor for defining the age threshold in adult and neonatal stem cell function. Am J Physiol Heart Circ Physiol. 2008; 295: H2308-14.

39. Wang Y, Hu F, Wang ZJ, et al. Administration of bone marrow-derived stem cells suppresses cellular necrosis and apoptosis induced by reperfusion of ischaemic kidneys in rats. Chin Med J (Engl). 2008; 121: 268-71.

40. Rehman J, Traktuev D, Li J, et al. Secretion of angiogenic and antiapoptotic factors by human adipose stromal cells. Circulation. 2004; 109: 1292-98.

41. Morigi M, Introna M, Imberti B, et al. Human bone marrow mesenchymal stem cells accelerate recovery of acute renal injury and prolong survival in mice. Stem Cells. 2008; 26: 2075-82.

42. Higashiyama R, Inagaki $Y$, Hong $Y Y$, et al. Bone marrow-derived cells express matrix metalloproteinases and contribute to regression of liver fibrosis in mice. Hepatology. 2007; 45: 213-22.

43. Kallis YN, Alison MR, Forbes SJ. Bone marrow stem cells and liver disease. Gut. 2007; 56: 716-2 